\title{
Phytosterols and Cardiovascular Disease
}

\author{
Umidakhon Makhmudova $^{1} \cdot$ P. Christian Schulze ${ }^{1} \cdot$ Dieter Lütjohann $^{2} \cdot$ Oliver Weingärtner $^{1}$ (I)
}

Accepted: 27 July 2021 / Published online: 1 September 2021

(c) The Author(s) 2021

\begin{abstract}
Purpose of Review Coronary heart disease is the leading cause of mortality worldwide. Elevated blood cholesterol levels are not only the major but also the best modifiable cardiovascular risk factor. Lifestyle modifications which include a healthy diet are the cornerstone of lipid-lowering therapy. So-called functional foods supplemented with plant sterols lower blood cholesterol levels by about $10-15 \%$.

Recent Findings In the recent revision of the ESC/EAS dyslipidemia guideline 2019, plant sterols are recommended for the first time as an adjunct to lifestyle modification to lower blood cholesterol levels. However, the German Cardiac Society (DGK) is more critical of food supplementation with plant sterols and calls for randomized controlled trials investigating hard cardiovascular outcomes. An increasing body of evidence suggests that plant sterols per se are atherogenic.

Summary This review discusses this controversy based on findings from in vitro and in vivo studies, clinical trials, and genetic evidence.
\end{abstract}

Keywords Cholesterol metabolism $\cdot$ Phytosterols $\cdot$ ABCG5/G8 $\cdot$ NPC1L1 $\cdot$ Atherosclerosis

\section{Introduction}

According to the World Health Organization (WHO, 2017), 17.9 million humans die each year from cardiovascular diseases, which accounts for a third of all deaths worldwide [1]. The most common manifestation among cardiovascular diseases is coronary heart disease (CHD). Low-density lipoprotein (LDL-C) levels correlate with coronary heart

This article is part of the Topical Collection on Cardiovascular Disease and Stroke

Oliver Weingärtner

oliver.weingaertner@med.uni-jena.de

Umidakhon Makhmudova

Umidakhon.Makhmudova@med.uni-jena.de

P. Christian Schulze

Christian.Schulze@med.uni-jena.de

Dieter Lütjohann

dieter.luetjohann@ukbonn.de

1 Klinik Für Innere Medizin I, Universitätsklinikum Jena, Am Klinikum 1, 07747 Jena, Germany

2 Institut für klinische Chemie und klinische Pharmakologie, Universitätsklinikum Bonn, Bonn, Germany disease (CHD) [2]. LDL-C reduction decreases the risk for CHD and major coronary events [3]. Therefore, LDL-C reduction is the central goal of the recently revised ESC/ EAS guidelines for the management of dyslipidemias: lipid modification to reduce cardiovascular risk and many other international guidelines such as the National Lipid Association (NLA) [4], USA, the National Institute for Health and Care Excellence (NICE) [5], and the American College of Cardiology/American Heart Association (ACC/AHA) [6] to name only a few. Of note, the ESC/EAS dyslipidemia guidelines included in the revised version of 2019 for the first time that plant sterols (phytosterols) are a recommended therapeutic strategy to lower blood cholesterol levels. The ESC/EAS joint guidelines recommend 2 g phytosterol supplementation in individuals with high cholesterol levels at intermediate and low cardiovascular risk; in those who do not qualify for pharmacotherapy, in high- and very-highrisk patients on top of pharmacotherapy who fail to achieve LDL-C-goals or who cannot be treated with statins, and in individuals with familial hypercholesterolemia [7••]. The American Heart Association, on the other hand, restricts the use of phytosterols to patients with familial hypercholesterolemia and for secondary prevention and emphasizes that more information is required to recommend plant sterols in 
the general population [6]. The National Institute for Health and Care (NICE) in the United Kingdom recommends that anyone with increased risk of CHD not use plant sterols or plant stanols as part of their cholesterol-lowering strategy [8]. Likewise, the German Federal Institute for Risk Assessment (BfR) does not recommend the use of plant sterolenriched foods and pushes that no more market approval should be awarded to phytosterol-enriched functional foods [9]. Finally, the Germany Cardiac Society (DGK) calls for randomized, controlled trials investigating hard cardiovascular outcomes for foods that are supplemented with plant sterols and criticizes the recently revised ESC/EAS recommendation [10•]. This review summarizes the current evidence on plant sterols and cardiovascular risk.

\section{Plant Sterol Biochemistry and Physiology}

Both cholesterol and phytosterols belong to the family of triterpenes. They have a tetracyclic ring and carbon-linked side chain. Plant sterols differ from cholesterol by structural modification within the side chain in position $\mathrm{C} 24$. Plant stanols are saturated sterols with a double-bind at the C5-atom in the B-ring [11]. The most common plant sterols in the diet are campesterol and $\beta$-sitosterol (they constitute about $65 \%$ and $30 \%$, respectively) and the most common stanols are $5 \alpha$-saturated stanols (generally plants have very little amounts of stanols) [11].

Cholesterol and phytosterols are absorbed in the small intestine (Fig. 1). They are solubilized and incorporated into micelles and absorbed via a specific carrier - NiemannPick C1-like protein 1 (NPC1L1) [12]. The heterodimer ATP binding cassette transporter G5 and G8 (ABCG5/8) secretes phytosterols and small amounts of cholesterol back into the intestinal lumen $[13,14]$. The same processes

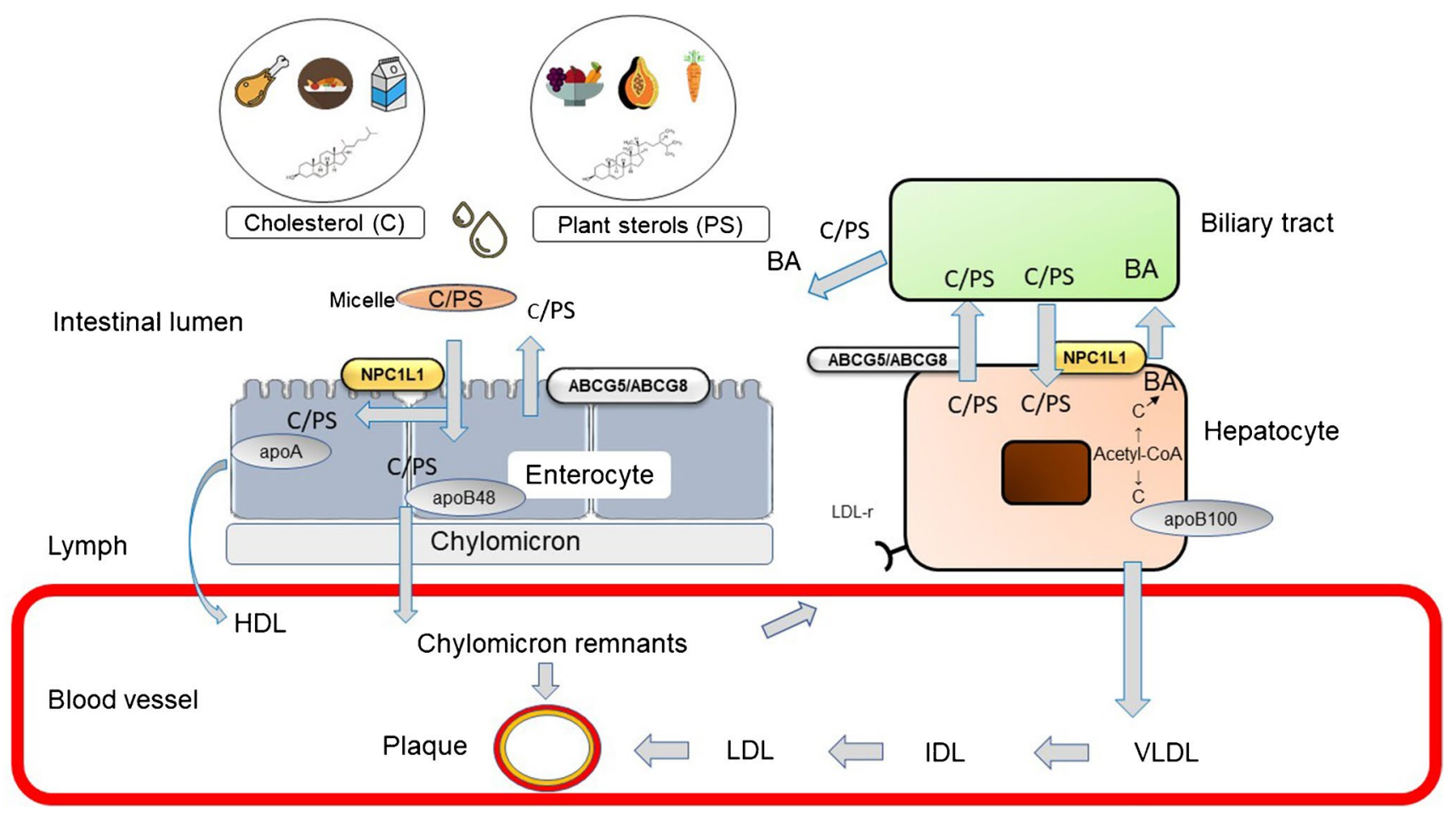

Fig. 1 Cholesterol and plant sterol metabolism. Cholesterol (C) and plant sterols (PS) from the diet are incorporated into micelles in the small intestine and are transported to the enterocyte mucosa via the sterol transporter Niemann-Pick C1-like 1 protein (NPC1L1). Free PS and "excess" $\mathrm{C}$ are secreted back into the lumen by the ABCG5/ABCG8 heterodimer tandem transporter. Esterified cholesterol and plant sterols are transported in chylomicrons, secreted into the lymph, converted to chylomicron remnants, and taken up in the liver, whereas small amounts of free C/PS leave the enterocyte via apoA-containing HDL. Chylomicron remnants also contribute to atherosclerotic plaque formation in the arterial wall. Thus, the hepatic pool of sterols consists of endogenously synthesized C and dietary $\mathrm{C} /$ PS. Also in the hepatocyte, NPC1L1 absorbs sterols and ABCG5/8 secretes them into the bile. Part of cholesterol is converted into bile acids (BA) which are transported in free and conjugated form by specific BA transporters into the bile. In the liver, very low-density cholesterol (VLDL) is formed from $\mathrm{C}$, lipoproteins (containing mostly apoB100), and tryglycerides. In the bloodstream, VLDL is converted to intermediate-density cholesterol (IDL) and low-density cholesterol (LDL). LDL is the main carrier of cholesterol in the bloodstream. Both C and PS accumulate in the arterial wall and are associated with cardiovascular events 
occur in the hepatocyte, where both NPC1L1 and ABCG5/8 are expressed. As a result of this selection, which can be interpreted as a "defense mechanism" against phytosterols, plasma plant sterol concentration is 1000 -fold lower than plasma cholesterol levels.

\section{Plant Sterols in Nutrition and Nutraceuticals}

Phytosterols are part of plant foods, mainly in unrefined vegetable oils, grains, nuts, and olive oil. A typical western diet contains equal amounts (approximately $400 \mathrm{mg}$ ) of both plant sterols and cholesterol each day. Unlike cholesterol, phytosterols are not synthesized in humans, phytosterols have no function in human organism and diet is their only source.

Cytellin - the first plant sterol product - was introduced to the market in the late $50 \mathrm{~s}$. Due to its low palatability and poor bioavailability, it was withdrawn in the 1985 [15]. In the mid-1990s, a margarine enriched with phytosterols - the first phytosterol containing functional food - was launched. Phytosterol-enriched low-fat milk and in margarines resulted in a 10-15\% LDL-C reduction [16], whereas fortified cereals reduce LDL-C by $5.4 \%$ [17]. Up to date, different food products enriched with phytosterols are available: milk, soy, yoghurt products; soy and fruit drinks; cereal; sausage etc. More than 300 million USD are spent annually on functional food enriched with phytosterols worldwide [18].

\section{Plant Sterols and Cardiovascular Risk}

\section{In Vitro Studies}

Phytosterol cellular uptake was studied in HepG2 and CaCo-2 cell lines. In both cell lines, incubation with phytosterols resulted in the reduction of cellular cholesterol levels $[19,20]$. Cytotoxic effects of phytosterols on human endothelial cells have been reported by Boberg and colleagues. They incubated human endothelial vein cells (HUVEC) with sitosterol for $72 \mathrm{~h}$, which resulted in contraction of HUVEC and increase of intracellular lactate dehydrogenase [21]. In another study, Bao and colleagues reported a sitosterol-induced necrotic death in macrophages, derived from mice [22]. The lesional necrosis of atherosclerotic plaque mainly consists of macrophages; therefore, the authors hypothesized that sitosterol-induced accelerated macrophage death leads to plaque necrosis, to plaque rupture, and eventually to cardiovascular events. They supported this hypothesis by findings from a previous study in which they demonstrated a decrease in lesional macrophages resulting in a decrease of plaque necrosis in vivo [23]. They also speculated that sitosterol possibly inhibits the caspase pathway in macrophages, since in their model, sitosterol induces necrosis, but not cell-programmed apoptosis [22].

\section{In Vivo Studies}

Animal studies demonstrate that a diet supplementation with phytosterols reduces serum cholesterol levels and atherosclerotic lesions [24-27]. However, there are also studies that demonstrate negative vascular effects. In apoE ${ }^{-/-}$mice on a western-type, we found that lipid-lowering with a plant sterol-enriched diet compared to ezetimibe treatment resulted in twice as much atherosclerotic lesion formation [28]. This result is of particular interest since both options of inhibition of cholesterol absorption resulted in comparable serum cholesterol levels of $400 \mathrm{mg} / \mathrm{dl}$. Similar results were obtained in apoE $^{-/-}$mice on a regular diet without cholesterol supplementation. Mice which were on a plant sterol-enriched diet demonstrated twice as much atherosclerotic lesions, compared to those treated with ezetimibe, even though serum cholesterol levels in both groups were $200 \mathrm{mg} / \mathrm{dl}$. Moreover, wild-type mice supplemented with phytosterol-enriched food had increased cerebral lesion size after cerebral ischemia and impaired endothelial-dependent vasorelaxation compared to mice on normal chow. Further, Chen et al. reported an elevation of blood pressure in rats fed with phytosterol-enriched food [29].

Plat and colleagues investigated oxidized phytosterols. They fed LDL-r ${ }^{-/}$mice with control diet, oxysterolenriched, and oxyphytosterol-enriched diet. The latter resulted in significant increase of oxyphytosterol amounts in atherosclerotic lesions compared to control and oxysterol-enriched diet. The proportion of severe atherosclerotic lesions was significantly higher on an oxysterol- and oxyphytosterol-enriched diet [30]. They concluded that oxidized phytosterols may contribute to the severity of atherosclerotic lesions. Although, in normal diet, only very small amounts of oxidized phytosterol can be found, they are elevated in the plasma of patients with sitosterolemia and small amounts can even be found in the plasma of healthy individuals [31].

$\mathrm{Yu}$ and colleagues generated ABCG5/8 knockout mice to elucidate the role of these genes. They observed a 30-fold increase in sitosterol concentration in these mice on chow diet [32]. When dietary cholesterol content was increased, plasma phytosterol levels fell by $\sim 50 \%$ (both in wild-type and ABCG5/8 knockout mice). Besides, liver and plasma cholesterol levels were decreased by $50 \%$ on chow diet, containing only very small amounts of cholesterol. Further analysis of knockout mice by $\mathrm{Yu}$ et al. and McDaniel et al. demonstrated that these mice had a normal phenotype comparable with that of wild-type mice. When fed with a high-phytosterol diet, they failed to gain weight, developed hepatosplenomegaly, and died prematurely. On a regular 
diet, they accumulated phytosterols in different tissues and organs and developed complex cardiac lesions [32, 33].

\section{Human Studies}

\section{Case Reports}

Abnormally high levels of phytosterols are found in patients with sitosterolemia. Sitosterolemia is a rare genetic disorder, caused by mutations in ABCG5 or ABCG8 located in chromosome 2 resulting in increased plasma phytosterol levels (not mainly sitosterol but also campesterol, stigmasterol, and avenisterols). In 1974, two sisters were diagnosed with this rare disease presenting with xanthomatas (a deposition of phytosterols and cholesterol in different organs, mainly in extensor areas) and elevated phytosterol plasma levels [34]. The causal genetic mutation on ABCG5/8 was discovered only several years later in 2001 [13]. The clinical phenotype of sitosterolemia is very heterogenic - from asymptomatic to fatal cases as consequence of premature coronary heart disease. These patients are often characterized by xanthomas, severe coronary heart disease, aortic stenosis, and early cardiovascular death. Some patients present with hematologic disorders, such as stomatocytic hemolysis and macrothrombocytopenia [35]. The youngest patient diagnosed with sitosterolemia - a 2-year-old girl had elevated LDL-C levels and tuberous and intertriginous xanthomas [36]. In another case, a 5-year-old girl died due to severe coronary three-vessel disease [37]. The discovery of this rare disease has raised the interest in plant sterol physiology and its potential damaging effects on the human organism.

\section{Case-Control and Retrospective Cohort Studies}

A meta-analysis of randomized clinical trials on lipidlowering efficacy of plant sterols demonstrated that plant sterols reduce LDL-C levels by $17 \%$. However, there is a great inter-individual variability [38••] and some studies have not found any LDL-C lowering effect of plant sterols at all $[39,40]$.

In a case-control study in females with documented coronary artery disease vs. healthy controls, elevated ratios of phytosterols to cholesterol were associated with increased cardiovascular risk [41]. Similar results were observed in men in the PROCAM (Prospective Cardiovascular Münster) study [42]. Our group demonstrated that among patients undergoing aortic valve replacement, those with a positive history of cardiovascular disease had an increased campesterol-to-lathosterol ratio in plasma and aortic valve cusps [43]. Correlation of enhanced phytosterol levels/ratio to cholesterol with cardiovascular risk and coronary heart disease was also reported in patients without diabetes history [44] and established CVD [45]. Glueck et al. analyzed phytosterol levels in 595 hypercholesterolemic subjects and its relation to the incidence of coronary heart disease in those individuals and their first-degree relatives. They found a weak correlation between phytosterol and cholesterol plasma levels and a positive correlation between the phytosterol concentrations and personal or family history of coronary heart disease [46]. Sudhop et al. also demonstrated a correlation between sitosterol, campesterol, sitosterol/cholesterol ratio, and campesterol/cholesterol ratio in individuals admitted to hospital for elective coronary artery bypass grafting [47].

On the other hand, there are case-control studies that show no effect on cardiovascular risk or a negative correlation of plasma phytosterol levels and cardiovascular disease. The prospective EPIC-Norfolk population study did not find any significant difference between those with coronary heart disease and healthy controls [48]. Similarly, the CORA study could not find any association between phytosterols and coronary heart disease [49].

\section{Cohort Studies and Randomized Clinical Trials}

LURIC (Ludwigshafen Risk and Cardiovascular Health Study) - a prospective cohort study with a total of 3,316 participants - demonstrated that plasma phytosterol levels were predictors of all-cause and cardiovascular mortality [50]. Another cohort study - MONIKA/KORA - demonstrated that in healthy men 35-64 years of age, higher phytosterol levels correlated with occurrence of myocardial infarction during 10-year follow-up [51]. On the other hand, a 22-year follow-up study of 232 men at high cardiovascular risk demonstrated that higher plant sterol levels are correlated with lower long-term mortality [52]. Most importantly, in patients admitted for coronary angiography for suspected coronary artery disease, we found that $7 \alpha$-hydroxycampesterol and their ratios to cholesterol were associated with cardiovascular events during a 5-year follow-up period [53•]. All the above-mentioned studies are prospective cohort studies. Unfortunately, to date, there is no prospective, placebo-controlled, randomized trial to address the impact of phytosterol diet supplementation on hard cardiovascular outcomes.

\section{Meta-analysis of Case-Control, Cross-Sectional, and Cohort Studies}

A meta-analysis based on data from 17 studies (4 case-control, 3 cohort, 5 cross-sectional, and 5 nested case-control) evaluated the effect of phytosterol plasma levels on cardiovascular risk. The authors of this meta-analysis concluded that plasma phytosterol levels are not associated with cardiovascular risk. However, the results of this meta-analysis are to be interpreted with caution. First, there are no 
standardized methods of phytosterol measurements, hence results from different laboratories may differ largely. Second, not all studies were appropriately adjusted to potential confounding variables. Finally, of 59 initially selected publications, only 17 were included in the meta-analysis - another 41 were excluded because no explicit phytosterol exposure levels were reported or they did not meet inclusion criteria of this meta-analysis [54].

\section{Genetic Studies}

Plasma sterol concentrations are regulated by $\mathrm{ABCG} / 8$ and NPL1C1. NPL1C1, which is expressed on the apical surface of enterocytes, is responsible for the intestinal absorption of both cholesterol and plant sterols [55], whereas ABCG5/8 reduces dietary sterol concentration in the plasma by pumping plant sterols and "excess" cholesterol back into the intestinal lumen [13]. Teupser et al. identified three variants of ABCG8 and ABO blood group locus, associated with increased plasma phytosterol concentration in humans. Around $10 \%$ of the variability in serum phytosterol levels in the normal population could be explained by these three variants. Teupser and colleagues conducted a meta-analysis of 11 different studies comprising over 13,000 cases with coronary heart disease and controls, and showed a positive correlation between those three alleles, serum phytosterol levels, and higher probability of coronary heart disease [56]. As early as 2010, Teupser and colleagues came to the conclusion that genetic variants that increase plasma plant sterol levels are associated with CAD.

A genome-wide study including sequence data of a total of 91,002 participants who were of European, African, or South Asian ancestry identified 15 distinct NPC1L1 inactivating mutations. Approximately 1 of 650 persons was a heterozygous carrier for one of these mutations. Even though heterozygous carriers of NPC1L1 inactivating mutations had a mean LDL-C level that was only $12 \mathrm{mg} / \mathrm{dl}$ lower than that of non-carriers, carrier status was associated with a relative risk reduction for $\mathrm{CAD}$ of $53 \%$. The authors concluded that the genetic inhibition of NPC1L1 may also lower the risk of coronary heart disease by reducing the absorption of plant sterols [57].

Only recently, Helgadottir and colleagues [58••] reported a large genetic study from Iceland, Denmark, and the UK, with 85,544 cases and 648,442 controls. They determined a genetic risk score (GRS) for ABCG5/8 and NPC1L1 lipid genes which are involved in plant sterol metabolism - and lipid genes, which are not involved in the plant sterol metabolism - such as PCSK9, apoB, HMG-CoA reductase, and LDL receptor. They identified variants of $\mathrm{ABCG} 5 / 8$ and NPC1L1, associated with a significant impact on non-HDL cholesterol and phytosterol levels. A predicted $1 \mathrm{mmol} / \mathrm{L}$ increase in non-HDL cholesterol for ABCG5/8 and NPC1L1 variants resulted in twofold increase of cardiovascular risk, whereas a $1 \mathrm{mmol} / \mathrm{L}$ non-HDL cholesterol increase for genes that affect only non-HDL cholesterol, but have no impact on plant sterol metabolism, such as PCSK9, apoB, HMG-CoA reductase, and LDL receptor, was associated with a 1.5 -fold increase of cardiovascular risk. The authors concluded that non-HDL cholesterol can only explain around $60 \%$ of the increase in cardiovascular risk and the remaining $40 \%$ must be due to other mechanisms. ABCG5/8 and NPC1L1 are not associated with other conventional cardiovascular risk factors. In contrast, ABCG5/8 and NPC1L1 variants have a consistent close relationship to plant sterols - making elevated plant sterol levels a plausible explanation for the excess CAD risk. The authors, therefore, concluded that dietary sterols such as plant sterols may contribute directly to atherogenesis, raising questions about the safety of supplementing food with phytosterols for the purpose of cardiovascular risk reduction.

\section{Safety Concerns Beyond the Cardiovascular System}

Besides proatherogenic effects, there are other safety concerns regarding phytosterols. As early as 2000, Ratnayake and colleagues found that vegetable oil rich in phytosterols makes red blood cells more rigid and less flexible and results in significant shortening of the lifespan of rats [59]. This finding leads to the ban of any phytosterol-enriched foods in Canada in 2003 [60].

Another concern coming from in vivo studies is the negative impact of phytosterols on hormonal status and the reproductive system of male and female rats [61, 62] and goldfish [63]. However, this finding could not be proven in humans. In 185 healthy volunteers, phytosterol consumption ( $1.6 \mathrm{~g} /$ day) for 1 year did not affect the reproductive hormone levels in both male and female participants [64].

Further, there is concern that phytosterols can interfere with the absorption of several fat-soluble vitamins — such as tocoferol and $\beta$-carotene $[64,65]$. The Scientific Committee on Food of the European Commission has significant safety issues and recommends the use of natural sources of $\beta$-carotene to compensate for the reduction of $\beta$-carotenes caused by long-term consumption of phytosterol-enriched foods [66].

\section{Conclusions}

The revised ESC/EAS guidelines for the management of dyslipidemias included for the first time a recommendation for plant sterols as part of lifestyle changes to reduce serum cholesterol levels. Recent genetic evidence suggests 
that plant sterols "per se" are atherogenic. These findings support the call for randomized controlled trials with hard cardiovascular outcomes prior to a general recommendation for plant sterols to lower serum cholesterol levels, as reiterated only recently by the German Cardiac Society (DGK).

Funding Open Access funding enabled and organized by Projekt DEAL.

\section{Declarations}

Human and Animal Rights and Informed Consent This article does not contain any studies with human or animal subjects performed by any of the authors

Conflict of Interest Oliver Weingärtner reports honoraria from Amgen, Novartis, Hexal, Fresenius, Sanofi-Aventis, Pfizer, and Akcea Therapeutics. The other authors declare that they have no conflict of interest.

Open Access This article is licensed under a Creative Commons Attribution 4.0 International License, which permits use, sharing, adaptation, distribution and reproduction in any medium or format, as long as you give appropriate credit to the original author(s) and the source, provide a link to the Creative Commons licence, and indicate if changes were made. The images or other third party material in this article are included in the article's Creative Commons licence, unless indicated otherwise in a credit line to the material. If material is not included in the article's Creative Commons licence and your intended use is not permitted by statutory regulation or exceeds the permitted use, you will need to obtain permission directly from the copyright holder. To view a copy of this licence, visit http://creativecommons.org/licenses/by/4.0/.

\section{References}

Papers of particular interest, published recently, have been highlighted as:

- Of importance

$\bullet$ Of major importance

1. WHO. Cardiovascular diseases, fact sheet. 2017. https://www. who.int/news-room/fact-sheets/detail/cardiovascular-diseases(cvds). Accessed 27 Mar 2011.

2. Stamler J. Is relationship between serum cholesterol and risk of premature death from coronary heart disease continuous and graded?: findings in 356222 primary screenees of the multiple risk factor intervention trial (MRFIT). JAMA. 1986;256:2823.

3. Efficacy and safety of cholesterol-lowering treatment: prospective meta-analysis of data from 90056 participants in 14 randomised trials of statins. Lancet 2005;366:1267-1278.

4. Jacobson TA, Maki KC, Orringer CE, et al. National lipid association recommendations for patient-centered management of dyslipidemia: part 2. J Clin Lipidol. 2015;9:S1-S122.e1.

5. NICE. Cardiovascular disease: risk assessment and reduction, including lipid modification. 2014. https://www.nice.org.uk/ guidance/cg181.

6. Lichtenstein AH, Deckelbaum RJ. Stanol/sterol ester-containing foods and blood cholesterol levels: a statement for healthcare professionals from the nutrition committee of the council on nutrition, physical activity, and metabolism of the American Heart Association. Circulation. 2001;103:1177-9.
7.• Mach F, Baigent C, Catapano AL, et al. 2019 ESC/EAS Guidelines for the management of dyslipidaemias: lipid modification to reduce cardiovascular risk: the Task Force for the management of dyslipidaemias of the European Society of Cardiology (ESC) and European Atherosclerosis Society (EAS). Eur Heart J. 2020;41:111-88. The revised ESC/EAS dyslipidemia guideline which included for the first time plant sterols as an option to lower blood cholesterol levels.

8. Cardiovascular disease: risk assessment and reduction, including lipid modification. National Institute for Health and Care Excellence (UK), London; 2016.

9. Bundesinstitut für Risikobewertung. Menschen mit normalen Cholesterinwerten sollten auf den Verzehr von Lebensmitteln mit zugesetzten Pflanzensterinen verzichten. 2008. https://mobil. bfr.bund.de $/ \mathrm{cm} / 343 /$ menschen_mit_normalen_cholesterinwert en.pdf.

10.• Kommission für Klinische Kardiovaskuläre Medizin der DGK, Weingärtner O, Landmesser U, März W, Katzmann JL, Laufs U. Kommentar zu den Leitlinien (2019) der ESC/EAS zur Diagnostik und Therapie der Dyslipidämien. Kardiologe. 2020;14:256-66. This review is the comment of the German Society of Cardiology (DGK) on the ESC/EAS dyslipidemia guidelines 2020 which calls for cardiovascular outcome studies prior to recommending plant sterols as a dietary supplement.

11. Valitova JN, Sulkarnayeva AG, Minibayeva FV. Plant sterols: diversity, biosynthesis, and physiological functions. Biochemistry (Mosc). 2016;81:819-34.

12. Davis HR, Zhu L, Hoos LM, et al. Niemann-Pick C1 like 1 (NPC1L1) is the intestinal phytosterol and cholesterol transporter and a key modulator of whole-body cholesterol homeostasis. J Biol Chem. 2004;279:33586-92.

13. Lee M-H, Lu K, Hazard S, et al. Identification of a gene, ABCG5, important in the regulation of dietary cholesterol absorption. Nat Genet. 2001;27:79-83.

14. Berge KE. Accumulation of dietary cholesterol in sitosterolemia caused by mutations in adjacent ABC transporters. Science. 2000;290:1771-5.

15. Weingartner O, Bohm M, Laufs U. Controversial role of plant sterol esters in the management of hypercholesterolaemia. Eur Heart J. 2008;30:404-9.

16. Miettinen TA, Puska P, Gylling H, Vanhanen H, Vartiainen E. Reduction of serum cholesterol with sitostanol-ester margarine in a mildly hypercholesterolemic population. $\mathrm{N}$ Engl $\mathrm{J}$ Med. 1995;333:1308-12.

17. Clifton PM, Noakes M, Sullivan D, Erichsen N, Ross D, Annison $\mathrm{G}$, et al. Cholesterol-lowering effects of plant sterol esters differ in milk, yoghurt, bread and cereal. Eur J Clin Nutr. 2004;58:503-9.

18. Phytosterols market size, share \& trends analysis report by product (beta-sitosterol, campesterol, stigmasterol), by application (pharmaceuticals, cosmetics, food ingredients), by region, and segment forecasts, 2020 - 2027. https://www.grandviewresear ch.com/industry-analysis/phytosterols-market.

19. Ho SS, Pal S. Margarine phytosterols decrease the secretion of atherogenic lipoproteins from HepG2 liver and $\mathrm{Caco} 2$ intestinal cells. Atherosclerosis. 2005;182:29-36.

20. Fahy DM, O'Callaghan YC, O'Brien NM. Phytosterols: lack of cytotoxicity but interference with $\beta$-carotene uptake in Caco-2 cells in culture. Food Addit Contam. 2004;21:42-51.

21. Boberg KM, Pettersen KS, Prydz H. Toxicity of sitosterol to human umbilical vein endothelial cells in vitro. Scand J Clin Lab Invest. 1991;51:509-16.

22. Bao L, Li Y, Deng S-X, Landry D, Tabas I. Sitosterolcontaining lipoproteins trigger free sterol-induced 
caspase-independent death in ACAT-competent macrophages. J Biol Chem. 2006;281:33635-49.

23. Feng B, Zhang D, Kuriakose G, Devlin CM, Kockx M, Tabas I. Niemann-Pick $\mathrm{C}$ heterozygosity confers resistance to lesional necrosis and macrophage apoptosis in murine atherosclerosis. Proc Natl Acad Sci. 2003;100:10423-8.

24. Moghadasian MH, McManus BM, Godin DV, Rodrigues B, Frohlich JJ. Proatherogenic and antiatherogenic effects of probucol and phytosterols in apolipoprotein E-deficient mice: possible mechanisms of action. Circulation. 1999;99:1733-9.

25. Moghadasian MH, McManus BM, Pritchard PH, Frohlich JJ. "Tall oil"-derived phytosterols reduce atherosclerosis in apoEdeficient mice. Arterioscler Thromb Vasc Biol. 1997;17:119-26.

26. Volger OL, Mensink RP, Plat J, Hornstra G, Havekes LM, Princen HMG. Dietary vegetable oil and wood derived plant stanol esters reduce atherosclerotic lesion size and severity in apoE3Leiden transgenic mice. Atherosclerosis. 2001;157:375-81.

27. Wilund KR, Yu L, Xu F, Vega GL, Grundy SM, Cohen JC, et al. No association between plasma levels of plant sterols and atherosclerosis in mice and men. ATVB. 2004;24:2326-32.

28. Weingärtner O, Lütjohann D, Ji S, et al. Vascular effects of diet supplementation with plant sterols. J Am Coll Cardiol. 2008;51:1553-61.

29. Chen Q, Gruber H, Swist E, Coville K, Pakenham C, Ratnayake WM, et al. Dietary phytosterols and phytostanols decrease cholesterol levels but increase blood pressure in WKY inbred rats in the absence of salt-loading. Nutr Metab (Lond). 2010;7:11.

30. Plat J, Theuwissen E, Husche C, Lütjohann D, Gijbels MJJ, Jeurissen M, Shiri-Sverdlov R, van der Made I, Mensink RP. Oxidised plant sterols as well as oxycholesterol increase the proportion of severe atherosclerotic lesions in female LDL receptor $^{+/-}$mice. Br J Nutr. 2014;111:64-70.

31. Grandgirard A, Martine L, Demaison L, Cordelet C, Joffre C, Berdeaux O, Semon E. Oxyphytosterols are present in plasma of healthy human subjects. Br J Nutr. 2004;91:101-6.

32. Yu L, Hammer RE, Li-Hawkins J, von Bergmann K, Lutjohann D, Cohen JC, Hobbs HH. Disruption of Abcg5 and Abcg8 in mice reveals their crucial role in biliary cholesterol secretion. Proc Natl Acad Sci. 2002;99:16237-42.

33. McDaniel AL, Alger HM, Sawyer JK, Kelley KL, Kock ND, Brown JM, Temel RE, Rudel LL. Phytosterol feeding causes toxicity in ABCG5/G8 knockout mice. Am J Pathol. 2013;182:1131-8.

34. Bhattacharyya AK, Connor WE. $\beta$-Sitosterolemia and xanthomatosis. J Clin Invest. 1974;53:1033-43.

35. Yoo E-G. Sitosterolemia: a review and update of pathophysiology, clinical spectrum, diagnosis, and management. Ann Pediatr Endocrinol Metab. 2016;21:7.

36. Buonuomo PS, Iughetti L, Pisciotta L, et al. Timely diagnosis of sitosterolemia by next generation sequencing in two children with severe hypercholesterolemia. Atherosclerosis. 2017;262:71-7.

37. Mymin D, Wang J, Frohlich J, Hegele RA. Aortic xanthomatosis with coronary ostial occlusion in a child homozygous for a nonsense mutation in ABCG8. Circulation. 2003;107:791-791.

38.• Jones PJH, Shamloo M, MacKay DS, et al. Progress and perspectives in plant sterol and plant stanol research. Nutr Rev. 2018;76:725-46. This review is the most comprehensive and up-to-date review on plant sterol research.

39. Denke MA. Lack of efficacy of low-dose sitostanol therapy as an adjunct to a cholesterol-lowering diet in men with moderate hypercholesterolemia. Am J Clin Nutr. 1995;61:392-6.

40. Weingärtner O, Bogeski I, Kummerow C, et al. Plant sterol ester diet supplementation increases serum plant sterols and markers of cholesterol synthesis, but has no effect on total cholesterol levels. J Steroid Biochem Mol Biol. 2017;169:219-25.
41. Rajaratnam RA, Gylling H, Miettinen TA. Independent association of serum squalene and noncholesterol sterols with coronary artery disease in postmenopausal women. J Am Coll Cardiol. 2000;35:1185-91.

42. Assmann G, Cullen P, Erbey J, Ramey DR, Kannenberg F, Schulte H. Plasma sitosterol elevations are associated with an increased incidence of coronary events in men: results of a nested case-control analysis of the Prospective Cardiovascular Münster (PROCAM) study. Nutr Metab Cardiovasc Dis. 2006;16:13-21.

43. Weingärtner $\mathrm{O}$, Weingärtner N, Scheller B, Lütjohann D, Gräber $\mathrm{S}$, Schäfers H-J, et al. Alterations in cholesterol homeostasis are associated with coronary heart disease in patients with aortic stenosis. Coron Artery Dis. 2009;20:376-82.

44. Weingärtner $O$, Lütjohann D, Vanmierlo T, Müller S, Günther L, Herrmann W, et al. Markers of enhanced cholesterol absorption are a strong predictor for cardiovascular diseases in patients without diabetes mellitus. Chem Phys Lipids. 2011;164:451-6.

45. Matthan NR, Pencina M, LaRocque JM, Jacques PF, D'Agostino RB, Schaefer EJ, et al. Alterations in cholesterol absorption/synthesis markers characterize Framingham Offspring Study participants with CHD. J Lipid Res. 2009;50:1927-35.

46. Glueck CJ, Speirs J, Tracy T, Streicher P, Illig E, Vandegrift J. Relationships of serum plant sterols (phytosterols) and cholesterol in 595 hypercholesterolemic subjects, and familial aggregation of phytosterols, cholesterol, and premature coronary heart disease in hyperphytosterolemic probands and their first-degree relatives. Metabolism. 1991;40:842-8.

47. Sudhop T, Gottwald BM, von Bergmann K. Serum plant sterols as a potential risk factor for coronary heart disease. Metabolism. 2002;51:1519-21.

48. Pinedo S, Vissers MN, von Bergmann K, Elharchaoui K, Lütjohann D, Luben R, et al. Plasma levels of plant sterols and the risk of coronary artery disease: the prospective EPIC-Norfolk population study. J Lipid Res. 2007;48:139-44.

49. Windler E, Zyriax B-C, Kuipers F, Linseisen J, Boeing H. Association of plasma phytosterol concentrations with incident coronary heart disease. Atherosclerosis. 2009;203:284-90.

50. Silbernagel G, Fauler G, Hoffmann MM, Lütjohann D, Winkelmann BR, Boehm BO, et al. The associations of cholesterol metabolism and plasma plant sterols with all-cause and cardiovascular mortality. J Lipid Res. 2010;51:2384-93.

51. Thiery J, Ceglarek U, Fiedler GM, Leichtle A, Baumann S, Teupser D, et al. Abstract 4099: elevated campesterol serum levels-a significant predictor of incident myocardial infarction: results of the population-based MONICA/KORA follow-up study 1994 to 2005. Circulation. 2006;114:II_884.

52. Strandberg TE, Tilvis RS, Pitkala KH, Miettinen TA. Cholesterol and glucose metabolism and recurrent cardiovascular events among the elderly: a prospective study. J Am Coll Cardiol. 2006; 48:708-14.

53. Fuhrmann A, Weingärtner O, Meyer S, et al. Plasma levels of the oxyphytosterol $7 \alpha$-hydroxycampesterol are associated with cardiovascular events. Atherosclerosis. 2018;279:17-22. This original publication provides evidence that oxysterols are associated with cardiovascular events.

54. Genser B, Silbernagel G, De Backer G, et al. Plant sterols and cardiovascular disease: a systematic review and meta-analysis. Eur Heart J. 2012;33:444-51.

55. Altmann SW. Niemann-Pick C1 like 1 protein is critical for intestinal cholesterol absorption. Science. 2004;303:1201-4.

56. Teupser D, Baber R, Ceglarek U, et al. Genetic regulation of serum phytosterol levels and risk of coronary artery disease. Circ Cardiovasc Genet. 2010;3:331-9. 
57. The Myocardial Infarction Genetics Consortium Investigators. Inactivating mutations in $\mathrm{NPC} L \mathrm{~L} 1$ and protection from coronary heart disease. N Engl J Med. 2014;371:2072-82.

58.• Helgadottir A, Thorleifsson G, Alexandersson KF, et al. Genetic variability in the absorption of dietary sterols affects the risk of coronary artery disease. European Heart Journal. 2020;41:261828 . This original publication provides genetic evidence that plant sterols "per se" are atherogenic.

59. Ratnayake WMN, L'Abbé MR, Mueller R, Hayward S, Plouffe L, Hollywood R, et al. Vegetable oils high in phytosterols make erythrocytes less deformable and shorten the life span of stroke-prone spontaneously hypertensive rats. J Nutr. 2000;130:1166-78.

60. Weingärtner O, Böhm M, Laufs U. Controversial role of plant sterol esters in the management of hypercholesterolaemia. Eur Heart J. 2009;30:404-9.

61. Malini T, Vanithakumari G. Antifertility effects of $\beta$-sitosterol in male albino rats. J Ethnopharmacol. 1991;35:149-53.

62. Solca C, Tint GS, Patel SB. Dietary xenosterols lead to infertility and loss of abdominal adipose tissue in sterolin-deficient mice. J Lipid Res. 2013;54:397-409.

63. Gilman CI, Leusch FDL, Carl Breckenridge W, MacLatchy DL. Effects of a phytosterol mixture on male fish plasma lipoprotein fractions and testis P450scc activity. Gen Comp Endocrinol. 2003;130:172-84.

64. Hendriks H, Weststrate J, van Vliet T, Meijer G. Spreads enriched with three different levels of vegetable oil sterols and the degree of cholesterol lowering in normocholesterolaemic and mildly hypercholesterolaemic subjects. Eur J Clin Nutr. 1999;53:319-27.

65. Gylling H, Puska P, Vartiainen E, Miettinen TA. Retinol, vitamin $\mathrm{D}$, carotenes and $\alpha$-tocopherol in serum of a moderately hypercholesterolemic population consuming sitostanol ester margarine. Atherosclerosis. 1999;145:279-85.

66. General view of the Scientific Committee on Food on the longterm effects of the intake of elevated levels of phytosterols from multiple dietary sources, with particular attention to the effects on $\beta$-carotene. European Comission. 2002. https://ec.europa.eu/ food/system/files/2020-12/sci-com_scf_out143_en.pdf.

Publisher's Note Springer Nature remains neutral with regard to jurisdictional claims in published maps and institutional affiliations. 